\title{
Padrões em contextos visuais e/ou figurativos: um estudo a partir das provas da OBMEP ${ }^{1}$
}

Standards in visual and/or figurative contexts: a study from the OBMEP proofs

\author{
Jussara Aparecida da Fonseca² \\ José Carlos Pinto Leivas ${ }^{3}$
}

\section{Resumo}

O presente trabalho tem por objetivo analisar como as Olimpíadas Brasileiras de Matemática das Escolas Públicas (OBMEP) têm explorado padrões visuais e/ou figurativos nas provas da primeira fase, realizadas com alunos do $6^{\circ}$ e $7^{\circ}$ anos do Ensino Fundamental (nível I). Partindo de uma fundamentação teórica sobre a conceituação, a classificação e a exploração de padrões no processo de ensino e aprendizagem matemática, identificamos questões presentes nas provas do nível I, realizadas entre 2005-2018, e as analisamos a partir de categorias relacionadas com as estratégias necessárias para suas respectivas resoluções. Como resultado, observamos que as questões propostas nas provas remetem tanto a padrões visuais e/ou figurativos de repetição quanto de crescimento, sendo que as estratégias necessárias para a resolução mostraram que é possível incentivar a observação e o reconhecimento de regularidades ou padrões desde os primeiros anos de escolaridade, acarretando benefícios na construção de outros conceitos matemáticos como, por exemplo, a noção de função.

Palavras-chave: Regularidades. Padrões visuais/figurativos. OBMEP.

\section{Introdução}

Diariamente, deparamo-nos com situações ou fenômenos do cotidiano que ocorrem com certa regularidade, os quais, comumente, chamamos de padrão. Para Vale (2012, p. 186), "a ideia fundamental num padrão envolve repetição e mudança. Conseguimos identificar um padrão naquilo que vemos ou imaginamos que pode acontecer".

\footnotetext{
${ }^{1}$ Trabalho realizado com apoio da Coordenação de Aperfeiçoamento de Pessoal de Nível Superior Brasil (CAPES) - Código de financiamento 001.

${ }^{2}$ Doutoranda do Programa de Pós-Graduação em Ensino de Ciências e Matemática da Universidade Franciscana (UFN), Professora do Instituto Federal Farroupilha - Campus Alegrete, jussara.mat@gmail.com.

${ }_{3}^{3}$ Doutor em Educação, Professor do Programa de Pós-Graduação em Ensino de Ciências e Matemática da Universidade Franciscana (UFN), leivasjc@ufn.edu.br.
} 
A observação e a identificação de regularidades ou padrões existentes em diferentes contextos possibilitam um melhor entendimento do mundo à nossa volta. Nessa direção, Barbosa (2013), destaca que a observação de padrões é uma atividade presente em diferentes áreas e contextos, e tem por objetivo perceber se existem e que contribuições trazem para o estabelecimento do padrão, permitindo compreender ou até prever fenômenos. Em particular, "[...] a matemática procura observar as regularidades em certos conjuntos para descrevê-los, caracterizá-los, generalizando um padrão que leve ao estabelecimento de definições e teoremas" (BARBOSA, 2013, p. 8).

À medida que a aprendizagem matemática avança, sobretudo na Educação Básica, torna-se cada vez mais necessário o domínio da capacidade de generalizar, a partir do reconhecimento de regularidades ou padrões. Isso contribui, sobretudo, para a compreensão do simbolismo presente em expressões matemáticas deduzidas a partir da observação de propriedades numéricas e/ou geométricas, evitando que tais expressões se tornem um emaranhado de símbolos sem significado.

Baqueiro (2016) verificou que contribuições algumas pesquisas brasileiras, realizadas entre 2003 e 2013 no âmbito de programas de pós-graduação na área da Educação Matemática, trazem sobre o tema generalizações de padrões matemáticos. A autora identificou 27 produções concluídas nesse período, as quais analisaram a partir de duas categorias: generalizações de padrões como tema secundário e como tema principal. Constatou que ambas as categorias apresentam contribuições em dois aspectos principais: o primeiro se refere à capacidade que as atividades envolvendo generalização de padrões têm para aguçar a curiosidade dos alunos, proporcionando a construção do pensamento algébrico; o segundo faz menção à importância da inserção de atividade de generalização de padrões em diferentes etapas da Educação Básica.

Assim, acreditando que as noções envolvidas na generalização de padrões matemáticos, em especial aqueles desenvolvidos a partir do estudo de padrões em contextos visuais e/ou figurativos, possam ser exploradas nos diferentes 
níveis da Educação Básica, desenvolvemos o presente trabalho. Neste sentido, o estudo tem por objetivo analisar como as Olimpíadas Brasileiras de Matemática das Escolas Públicas (OBMEP) têm explorado padrões visuais e/ou figurativos nas provas do nível I (primeira fase), destinadas a alunos do $6^{\circ}$ e $7^{\circ}$ anos do Ensino Fundamental.

Para tanto, realizamos um estudo teórico referente à exploração de padrões, com aporte principal em trabalhos das pesquisadoras Isabel Vale e Teresa Pimentel. Essa fundamentação foi subsídio para o estudo das questões das provas da OBMEP nível I (primeira fase), nos possibilitando identificar, classificar e analisar aquelas que abordam padrões em contextos visuais e/ou figurativos. Apresentamos, no decorrer deste artigo, os resultados encontrados nesse processo.

\section{Revisão de literatura}

Observar e identificar regularidades ou padrões nos mais variados contextos, buscando determinar o padrão estabelecido, auxilia na compreensão de um determinado acontecimento ou fenômeno. Na matemática não é diferente, visto que encontrar regularidades ou padrões que levem a um processo de generalização e abstração é uma das características da construção dos conhecimentos matemáticos.

Vale e Pimentel (2011) apontam que a utilização e a exploração de padrões nas aulas de matemática incentivam as conexões entre números, álgebra e geometria, originando diferentes representações e a abordagem de conceitos diversos.

Nessa linha de argumentação, Barbosa e Vale (2013, p. 3073) ressaltam que, no processo de ensino e aprendizagem da matemática, em especial na Educação Básica, "a exploração de padrões promove a formulação e justificação de generalizações, facilitando, em particular, a transição da aritmética para a álgebra e o desenvolvimento de capacidades de ordem superior". 
Esse é um ponto importante para o estudo de regularidades e padrões, uma vez que tomá-los como ponto de partida para a construção do raciocínio algébrico possibilita aos alunos a construção de relações entre o que é observado em uma sequência de situações, buscando uma relação para um caso geral. Além disso, essa metodologia de trabalho evita que os resultados se tornem um conjunto de fórmulas ou símbolos sem significados.

Nessa direção, Skemp (1989, p. 104) assinala que "símbolos são excelentes servos, mas maus mestres" (tradução nossa), pois não são capazes de produzir conhecimento por si só. Para evitar tal situação, é preciso compreensão, desenvolvida pela assimilação mútua entre o sistema simbólico e a estrutura conceitual.

Corroborando, Vale e Pimentel (2011) apontam que o insucesso na aprendizagem matemática pode estar ligado ao apelo excessivo dado à memorização sem compreensão. Além disso, as autoras ressaltam que

O primeiro passo para aprender a pensar matematicamente é aprender a descobrir padrões e estabelecer conexões. A procura de padrões deve constituir o núcleo das aulas em todos os temas, já que eles surgem nas fórmulas que descobrimos, nas formas que investigamos e nas experiências que fazemos. (VALE; PIMENTEL, 2011, p. 1).

Mas, o que é padrão? As pesquisadoras Teresa Pimentel e Isabel Vale, após desenvolverem por vários anos investigações sobre padrões, identificaram a similaridade entre o significado de padrão e o de regularidade, propondo uma definição que abrange as duas noções:

Padrão ou regularidade é uma relação discernível, apreendida de modo pessoal, num arranjo de qualquer natureza, através de um processo mental que pode ser partilhado, e que corresponde a uma estrutura traduzível por uma lei matemática. (PIMENTEL; VALE, 2012, p. 33).

Deste modo, o estudo de padrões ou regularidades presume a identificação e compreensão de uma relação entre um conjunto de elementos que podem ser numéricos, geométricos ou de outra natureza, a qual pode ser descrita por uma expressão matemática. 
Essa característica inerente à exploração de padrões ou regularidades "é algo de muito poderoso que, uma vez detectado pode conduzir a um enriquecimento da exploração, designadamente permitindo a explicação e a justificação da generalização feita". (PIMENTEL; VALE, 2012, p. 33).

Quanto à classificação de padrões, Vale (2012) aponta que um padrão pode ser de repetição ou de crescimento. Nas palavras da pesquisadora: "um padrão será de repetição quando há um motivo identificável que se repete de forma cíclica indefinidamente. Um padrão será de crescimento quando cada termo muda de forma previsível em relação ao anterior". (VALE, 2012, p. 168).

Entre os padrões de repetição, cabe destacar um tipo particular, denominado friso. Segundo Nardelli (2015), o friso é caracterizado por ser periódico e ter uma largura constante e finita. Além disso, conforme o autor, o friso também é descrito por um dos seguintes grupos de simetria: (i) translação, (ii) translação e reflexão vertical, (iii) translação e reflexão horizontal, (iv) translação, reflexão deslizante, (v) translação e rotação, (vi) translação, reflexão deslizante e rotação e (vii) translação, reflexão horizontal e reflexão vertical.

Para Vale (2013, p. 70), padrões de repetição e de crescimento envolvem, respectivamente, dois tipos de generalização:

A generalização próxima, que se refere à descoberta do termo seguinte, que pode ser obtido por contagem, desenho ou por recurso a uma tabela, e que normalmente envolve relações recursivas, e a generalização distante, que implica a descoberta do padrão e exige a compreensão da lei de formação, ou seja, de uma regra geral expressa matematicamente, e requer a procura de relações funcionais.

Além disso, de acordo com a autora, padrões de repetição e de crescimento podem ser de natureza numérica e/ou visual/figurativa, sendo este segundo tipo o que merece destaque, pois permite que os alunos pensem visualmente, o que pode conduzi-los ao processo de generalização, a partir do raciocínio indutivo. Além disso, "contextos figurativos são mais intuitivos para a maior parte dos alunos e, em particular, para os dos níveis mais elementares e/ou com fragilidades no conhecimento matemático" (VALE, 2013, p. 71). 
Pimentel e Vale (2012) ressaltam que padrões visuais e/ou figurativos devem ser explorados, sobretudo com alunos nos anos inicias de escolaridade, uma vez que esse tipo de padrão auxilia na determinação de relações e conduz ao processo de generalização.

Ainda segundo as autoras, padrões figurativos e/ou visuais permitem a ligação entre várias formas de representação e a necessidade de consistências entre as diferentes representações possibilita "o enriquecimento da compreensão da estrutura matemática subjacente, conduzindo, de modo mais eficaz, a conjectura e generalização, a explicação e argumentação, e, em última análise, à prova (PIMENTEL; VALE, 2012, p. 29)

De acordo com Barbosa e Vale (2013, p. 3080), o contexto figurativo é um bom elemento, nas aulas de matemática, para o aluno identificar um padrão, "uma vez que facilita a atribuição de significado às ideias exploradas, e consequentemente a compreensão, potenciando o pensamento flexível e um reconhecimento intuitivo da estrutura dos padrões".

Vale e Pimentel (2013, p. 109) defendem o uso de padrões em contextos visuais e/ou figurativos, indicando três vantagens:

(1) facilita a tomada de contacto com a tarefa e a sua exploração inicial, de um modo que talvez fosse impossível num contexto puramente numérico por insuficiência de conhecimentos ou flexibilidade numérica incipiente; (2) permite um aprofundamento de conceitos matemáticos envolvidos e 0 estabelecimento de conexões entre temas matemáticos, ao relacionar os contextos figurativo e numérico; e (3) a descoberta da consistência entre os vários tipos de representação do padrão permite um alargamento de vistas sobre o arranjo que amplia a compreensão, e proporciona, de um modo muito mais fecundo, a generalização e a explicação.

Quanto à descoberta de padrões, Vale (2013) destaca que 'ver' um padrão é o primeiro passo para sua exploração. Nesse contexto, 'ver' vai muito além do que é perceptível pelo sentido da visão, visto que faz referência à visualização em sentido amplo, isto é, traz como consequência a relação com os componentes do raciocínio que são mobilizados para identificar e relacionar as características e regularidades de um determinado padrão. 
Para a autora, a visualização é importante na aprendizagem matemática porque "não está relacionada somente com a mera ilustração, mas também por ser reconhecida como uma componente do raciocínio, da resolução de problemas e mesmo da prova" (VALE, 2012, p. 188).

Na mesma direção, Arcavi (2003) define visualização como:

A capacidade, o processo e o produto de criação, interpretação, uso e reflexão sobre figuras, imagens, diagramas, em nossas mentes, em papel ou com ferramentas tecnológicas, com o objetivo de retratar e comunicar informações, pensar e desenvolver ideias anteriormente desconhecidas e avançando na compreensão. (ARCAVI, 2013, p. 217, tradução nossa).

Dessa forma, percebemos que a visualização tem importante papel na aprendizagem matemática, em particular na exploração de padrões. Trata-se de um componente relevante para a compreensão de diferentes conceitos matemáticos, assim como das relações entre eles.

Com base no exposto sobre regularidades e padrões na construção da aprendizagem matemática, constatamos que padrões em contextos visuais e/ou figurativos se mostram uma boa opção para o desenvolvimento da habilidade de visualização desde os anos iniciais do Ensino Fundamental. Esse saber será indispensável para a construção do raciocínio mais avançado, necessário nos processos de generalização e abstração.

\section{Encaminhamentos metodológicos}

Em nosso estudo, optamos pela análise documental, que "pode se constituir numa técnica valiosa de abordagem de dados qualitativos, seja complementando as informações obtidas por outra técnica, seja desvelando aspectos novos de um tema ou problema" (LÜDKE; ANDRÉ, 2013, p. 44).

Os documentos utilizados foram as provas da primeira fase da OBMEP, destinadas aos alunos do 6ํㅡ e 7ํan anos, realizadas entre os anos de 2005 e 2018.

O processo de análise foi dividido em quatro etapas. Na primeira, identificamos em quais provas houve ocorrência de questões abordando padrões visuais e/ou figurativos; na segunda, classificamos as questões quanto ao tipo de 
padrão visual e/ou figurativo: de repetição ou de crescimento; na etapa seguinte, solucionamos todas as questões para verificar os construtos matemáticos necessários para sua resolução; por fim, na quarta etapa, categorizamos as questões conforme os critérios necessários para suas respectivas resoluções.

No próximo tópico, detalharemos todas as etapas realizadas, bem como as reflexões suscitadas a partir dos resultados encontrados.

\section{Resultados e discussões}

A OBMEP foi criada em 2005, pelo Instituto Nacional de Matemática Pura e Aplicada (IMPA), com o apoio da Sociedade Brasileira de Matemática (SBM). Essa iniciativa surgiu como uma ação para estimular os alunos dos anos finais do Ensino Fundamental, assim como do Ensino Médio, em ambos os casos, de escolas públicas, a estudarem matemática, visando identificar talentos na área.

Entre os objetivos da OBMEP, estão: incentivar o estudo da matemática; colaborar com o ensino da matemática na Educação Básica, disponibilizando materiais didáticos; reconhecer jovens talentos na matemática e incentivar seu ingresso em cursos superiores nas áreas científicas e tecnológicas; estimular o aperfeiçoamento de professores da Educação Básica e propiciar a inclusão social por intermédio da disseminação do conhecimento.

Desde sua criação, até o ano atual, várias ações e programas vinculados a OBMEP foram desenvolvidos para incrementar a atuação e a ampliação das olimpíadas. São eles: Programa de Iniciação Científica Jr. (PIC), Portal da Matemática, Banco de Questões e Provas Antigas, Portal Clubes de Matemática, Polos Olímpicos de Treinamento Intensivo (POTI), Programa de Iniciação Científica e Mestrado (PICME) e Programa OBMEP na Escola.

A OBMEP é organizada em três níveis, de acordo com o grau de escolaridade dos alunos participantes: o primeiro é voltado a alunos do $6^{\circ}$ e $7^{\circ}$ anos do Ensino Fundamental; o segundo é destinado a alunos do $8^{\circ}$ e $9^{\circ}$ anos do Ensino Fundamental; e o terceiro é para alunos do Ensino Médio. 
Em todos os níveis, a OBMEP é realizada em duas etapas. A primeira corresponde a uma prova de 20 questões de múltipla escolha e a segunda contempla uma prova com seis questões dissertativas. Nessa segunda fase, participam apenas 5\% daqueles que atingiram o melhor desempenho na primeira.

Os alunos com melhores desempenhos são premiados com medalhas de ouro, prata e bronze. Também lhes é ofertada a oportunidade de participar do PIC, com direito ao recebimento de uma bolsa de Iniciação Científica Jr. financiada pelo Conselho Nacional de Desenvolvimento Científico e Tecnológico (CNPq).

Além da premiação a alunos medalhistas, existe a categoria de certificado de menção honrosa, destinada a alunos que apresentaram um desempenho satisfatório. Professores de alunos medalhistas também são premiados com a participação no Programa OBMEP na Escola, recebendo um diploma de homenagem e um livro de apoio à formação matemática, de acordo com critérios definidos pela OBMEP. Do mesmo modo, escolas e secretarias de educação de alunos medalhistas também são premiadas com diplomas alusivos à premiação.

Em 2017, a OBMEP passou a contar com a participação de alunos de escolas particulares, e em 2018, a olimpíada foi estendida a alunos dos $4^{\circ}$ e $5^{\circ}$ anos do Ensino Fundamental, em calendário diferente das provas dos outros níveis, e com algumas especificidades relacionadas a esse público, como, por exemplo, a realização de uma única etapa de provas.

As provas da OBMEP, nos diferentes níveis e etapas, abordam diversos conteúdos matemáticos, entre eles, o de regularidades ou padrões em contextos visuais e/ou figurativos. Com o intuito de verificar como essa temática é abordada nas olimpíadas, analisamos as provas referentes à primeira etapa do nível 1, realizadas entre os anos de 2005 e 2018.

Nas provas analisadas, verificamos a incidência de 10 questões abordando padrões em contextos visuais e/ou figurativos, divididas em padrões de repetição e de crescimento, como apresentado no Quadro 1. Cabe ressaltar que, além das 
questões analisadas, há também problemas que abordam padrões numéricos, os quais foram excluídos das análises por não configurarem o foco deste trabalho.

\begin{tabular}{|c|c|l|}
\hline ANO & No DE QUESTÕES & \multicolumn{1}{|c|}{ TIPO DE PADRÃO } \\
\hline 2007 & 1 & Repetição (questão 14) \\
\hline 2008 & 1 & Repetição (questão 15) \\
\hline 2012 & 2 & Repetição (questão 9) e crescimento (questão 2) \\
\hline 2014 & 3 & Repetição (questões 15 e 18) e crescimento (questão 19) \\
\hline 2015 & 1 & Repetição (questão 17) \\
\hline 2016 & 1 & Crescimento (questão 13) \\
\hline 2018 & 1 & Crescimento (questão 11) \\
\hline
\end{tabular}

Quadro 1: quantitativo e classificação das questões da OBMEP (nível 1)

Fonte: elaborado pelos autores

Ao examinarmos as seis atividades de padrões visuais e/ou figurativos de repetição, tendo em vista que são aquelas que se repetem de forma sistemática, organizamos essas questões em três grupos, de acordo com as estratégias utilizadas em suas respectivas resoluções.

O primeiro grupo engloba três atividades que solicitam a determinação de um elemento em uma dada posição $n$ de uma sequência de termos. Para resolver as questões, é necessário que o aluno identifique a unidade de repetição, ou seja, o elemento que garante sua estrutura cíclica.

Reconhecer a unidade de repetição é fator essencial para 0 desenvolvimento de problemas com padrões de repetição. Sobre esse fato, Vale e Pimentel (2011, p. 3) ressaltam que "é muito importante levar o aluno a identificar o grupo de repetição, pois só assim poderá abordar questões sobre a globalidade abstraindo dos objetos concretos".

As questões que categorizamos neste grupo foram: questão 14 da prova de 2007, questão 9 da prova de 2012 e questão 15 da prova de 2014. Para exemplificar essa situação, apresentamos, no Quadro 2, uma dessas atividades, seguida de uma possível estratégia de resolução. 
Guilherme começa a escrever os números naturais em figuras triangulares de acordo com o padrão abaixo:

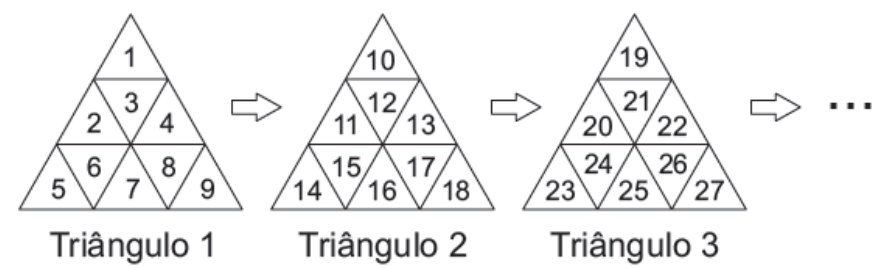

Nomeando as casas de cada um desses triângulos com as letras $A, B, C, D$, E, F, G, $\mathrm{H}$ e I, como na figura ao lado, ele pode codificar cada número natural por meio do número do triângulo e da letra da casa em que ele aparece.

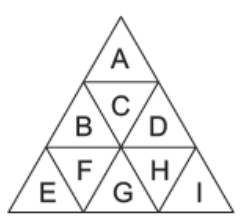

Por exemplo, o número 5 é codificado por $1 \mathrm{E}$, pois aparece na casa $\mathrm{E}$ do Triângulo 1. Já o número 26 é codificado por $3 \mathrm{H}$, pois aparece na casa $\mathrm{H}$ do Triângulo 3 . Como Guilherme codifica o número 2014 ?

Quadro 2: enunciado da questão 15 da prova da OBMEP - nível I de 2014 Fonte: www.obmep.org.br

Para resolver essa questão, podemos notar que, em cada triângulo, cabem nove números. Desse modo, precisamos determinar quantos triângulos são necessários para chegarmos ao número 2014. Esse valor é definido a partir da divisão de 2014 por 9 , da qual obtemos $2014 \div 9=223 \times 9+7$. Isso implica dizer que para o número 2014, são necessários 223 triângulos completos e a ocupação do 224ํ triângulo até a sétima casa. Logo, 2014 será codificado como 224G.

Nessa atividade, a unidade de repetição é o número 9. É esse valor que determina de que forma o padrão irá se repetir ciclicamente. Com a identificação da unidade, basta realizar a correspondência, de acordo com dados do problema. As outras duas atividades desse grupo têm soluções análogas, sendo que a identificação da unidade de repetição é essencial para a resolução.

O grupo seguinte contempla duas atividades, a saber: a questão $15 \mathrm{da}$ prova de 2008 e a questão 17 da prova de 2015. Em ambas, a unidade de repetição deve ser identificada em duas sequências distintas, mas relacionadas. No Quadro 3, apresentamos uma dessas atividades e, logo após, discorremos sobre uma possibilidade de resolução. 
Joãozinho tem um tabuleiro como o da figura, no qual há uma casa vazia, uma casa com uma peça preta e as demais casas com peças cinzentas. Em cada movimento, somente as peças que estão acima, abaixo, à direita ou à esquerda da casa vazia podem se movimentar, com uma delas ocupando a casa vazia. Qual é o número mínimo de movimentos necessários para Joãozinho levar a peça preta até a casa do canto superior esquerdo, indicada pelas setas?

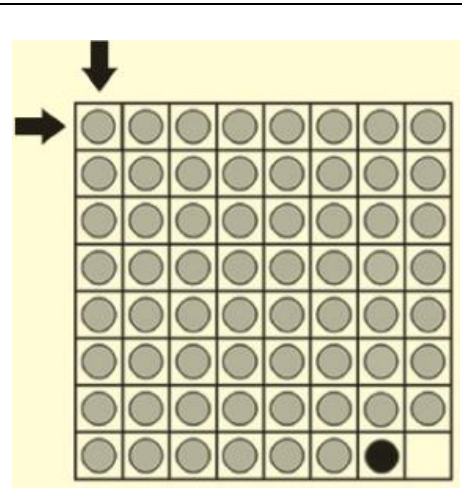

Quadro 3: enunciado da questão 17 da prova da OBMEP - nível I de 2015 Fonte: www.obmep.org.br

$\mathrm{Na}$ resolução dessa atividade, devemos perceber que, para a peça preta ser levada até a casa indicada, com o menor número de passos possível, ela deve ser movida sempre para cima ou para a esquerda, nunca para baixo ou para a direita, pois assim estaria retrocedendo, o que aumentaria o número de passos necessários. Verifiquemos se é melhor o primeiro movimento ser para esquerda ou para cima. Se a peça for movida para a esquerda, são necessários três movimentos para que ocupe a casa diretamente ao lado; caso seja movida para cima, são necessários, no mínimo, cinco passos. Assim, a melhor opção é mover a peça para a esquerda no primeiro movimento. Na Figura 1, representamos a nova configuração do tabuleiro a partir desta movimentação.

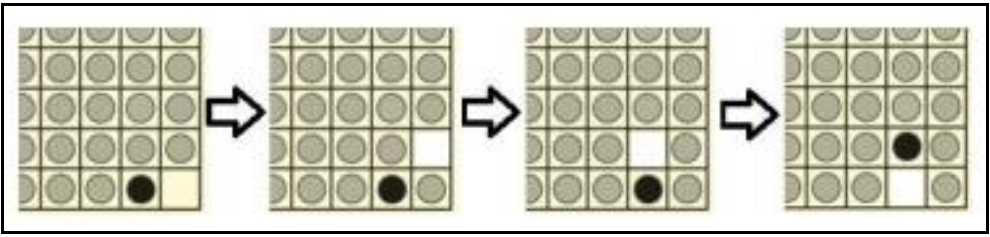

Figura 1: posição da peça preta no tabuleiro após a primeira movimentação.

Fonte: www.obmep.org.br

Para realizar o segundo movimento, precisamos analisar, novamente, se é mais vantajoso deslocar a peça para a esquerda ou para cima. Se a peça for movida para a esquerda, serão necessários cinco movimentos para ocupar a casa diretamente ao lado; se for deslocada para cima, bastam apenas três 
movimentos. Logo, para garantir o menor número de movimentos nessa jogada, a peça preta deve ser movida para cima, ocupando a posição mostrada na Figura 2.

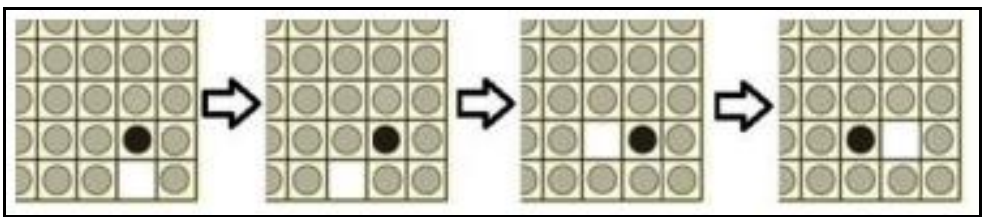

Figura 2: posição da peça preta no tabuleiro após a segunda movimentação. Fonte: www.obmep.org.br

Ao final da segunda movimentação (Figura 2), a peça preta passa a ocupar uma posição semelhante à configuração inicial do tabuleiro (casa vazia do lado direito da peça preta). Assim, no terceiro movimento, a peça deve ser movida para a esquerda, repetindo a primeira movimentação, assumindo uma posição semelhante à ocupada após a primeira movimentação. Logo, para a peça preta alcançar a casa indicada no tabuleiro, deverá ser movida: para esquerda $\rightarrow$ para cima $\rightarrow$ para esquerda $\rightarrow$ para cima $\rightarrow$..., e assim sucessivamente.

Precisamos determinar quantas vezes a peça irá ser movida para esquerda e para cima, depois multiplicar pelo número de movimentos mínimos necessários para cada tipo de movimentação (três). Analisando o tabuleiro, percebemos que, alternadamente, são necessárias seis movimentações para esquerda e sete para cima. Portanto, para levar a peça preta até a casa indicada, precisamos de, no mínimo, $6 \times 3+7 \times 3=18+21=39$ movimentos.

As duas questões classificadas nesta categoria podem ser consideradas como um padrão de repetição mais complexo por duas razões. Primeiro, porque o próprio enunciado é complicado para nível de ensino ao qual se destinada; e segundo, porque envolvem duas unidades de repetição, sendo, no caso da questão analisada são: (I) quantidade de movimentos para mover a peça para esquerda e para cima; (II) número de vezes que os dois processos serão realizados, de forma a garantir o menor número de movimentações.

Além disso, há também a complexidade envolvendo a própria figura, que não apresenta a regularidade de forma direta e explícita. Nesse sentido, Sasman, Olivier e Linchevski (1999 apud BARBOSA; VALE, 2013, p. 3076) destacam que 
existem figuras transparentes e figuras não transparentes. Para os autores, "no primeiro caso, a regra associada ao padrão está subjacente, de forma evidente, na estrutura das figuras da sequência, o que não acontece no segundo caso".

Por fim, o terceiro grupo das questões com padrão de repetição conta com uma atividade em que a determinação da unidade de repetição é necessária como uma estratégia de contagem. No Quadro 4, apresentamos o enunciado da atividade, e, após, algumas estratégias de resolução.

Gustavo fez uma tira com 300 hexágonos, fixando-os pelos lados comuns com um adesivo redondo, como na figura. Quantos adesivos ele usou?

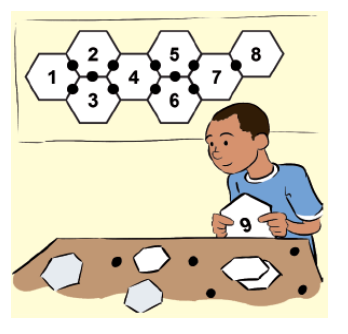

Quadro 4: enunciado da questão 18 da prova da OBMEP - nível I de 2014 Fonte: www.obmep.org.br

Podemos elencar duas estratégias de resolução para responder a atividade. Na primeira, verificamos que, para fixar um trio de hexágonos, Gustavo utiliza três adesivos, para unir o primeiro trio ao segundo, ele necessita de dois adesivos, o segundo ao terceiro, mais três, e assim sucessivamente, com exceção do último trio, que não será conectado a nenhum outro. Como, ao todo, são 300 hexágonos, podem ser formados 100 trios, que serão conectados uns aos outros. Portanto, Gustavo precisa de 498 adesivos $(3 \times 100+2 \times 99=498)$.

Na segunda estratégia, é necessário notar que cada trio de hexágonos utiliza cinco adesivos, com exceção do último, em que são utilizados apenas três adesivos. Como ao todo são 100 trios, em 99 são utilizados cinco adesivos e em 1 (o último) apenas três adesivos. Logo, o total de adesivos será: $5 \times 99+3=498$.

Esse tipo de atividade difere daquelas do primeiro grupo, porque o padrão não é apresentado de forma explícita. Ela depende da estratégia de resolução que cada um pode elaborar para a contagem dos elementos envolvidos. De certo modo, podemos afirmar que o padrão será criado, e não identificado pelo sujeito. 
Para Vale (2013, p. 73), as atividades de contagem em situações visuais e/ou figurativas permitem uma flexibilidade de pensamento quanto ao nível de estratégias que podem ser elaboradas. Nas palavras da autora, "os alunos devem ter experiências em diferentes contextos, de modo a serem estimulados a procurar diferentes modos de ver, optando pelo modo de contagem mais eficaz".

Em vista do que apresentamos, concluímos que as atividades de padrões visuais e/ou figurativos de repetição presentes na prova da OBMEP conseguem despender diferentes raciocínios e mecanismos de resolução que podem favorecer a capacidade de generalização. Isso porque os alunos são levados a explorar a forma de organização dos padrões, procurando relações entre os elementos que os constituem quando buscam a unidade de repetição.

Tais características vão ao encontro do que afirmam Barbosa e Vale (2013, p. 3074), "a identificação da unidade de repetição e a compreensão da estrutura global do padrão permitem ao aluno ir além do mero processo de continuação do padrão, a generalização distante, abrindo assim o caminho para a abstração".

Agora, voltando nossa atenção às questões classificadas como padrões de crescimento, considerando que é o tipo de padrão em que cada novo termo muda conforme uma condição do termo anterior, verificamos que estas podem ser separadas em dois grupos, conforme discutiremos a seguir.

No primeiro, encontramos duas questões: número 2 da prova de 2012 e número 11 da prova de 2018. Em ambas, são dados os primeiros membros de uma sequência e solicitados, a partir do padrão que pode ser observado, a quantidade de elementos de um termo, em determinada posição. No Quadro 5, mostramos uma dessas atividades e, a seguir, discutimos sua resolução.

Janaína faz torres com cartões, seguindo o padrão da figura. A primeira torre foi feita com 2 cartões, a segunda com 7, a terceira com 15 e assim por diante. Quantos cartões ela deve acrescentar à décima torre para obter a décima primeira?

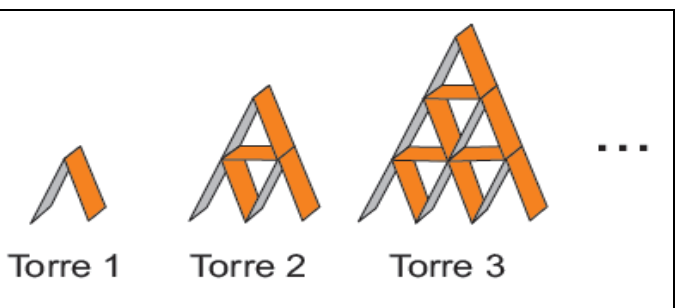

Quadro 5: enunciado da questão 11 da prova da OBMEP - nível I de 2018 Fonte: www.obmep.org.br 
Para resolver essa questão, podemos observar que, da torre 1 para a torre 2, foram acrescentados cinco cartões: dois na primeira fileira e três para formar a segunda fileira, ou seja, $5=2+1 \times 3$. Do mesmo modo, da torre 2 para a torre 3 , foram acrescentados oito cartões: dois na primeira fileira e dois grupos de três cartões para formar a segunda e a terceira fileira, isto é, $8=2+2 \times 3$. Continuando o processo, da torre 3 para a torre 4, foram acrescentados onze cartões: dois na primeira fileira e três grupos de três para formar a segunda, a terceira e a quarta fileiras, ou seja, $11=2+3 \times 3$. Assim, para cada nova torre $n$, são acrescentados dois cartões (na primeira fileira), adicionados a $(n-1)$ grupos de três cartões. Logo, para formar a torre 11, são necessários $2+(11-1) \times 3=32$ cartões.

Esse é um tipo clássico de problemas envolvendo padrões de crescimento, os quais, comumente, são utilizados para fazer uma ligação entre a aritmética e a álgebra, uma vez que podemos representar a relação entre os termos de cada padrão e sua posição através de uma expressão algébrica.

É o tipo de problema que leva ao raciocínio funcional, conduzindo a generalização distante (VALE, 2012, 2013, VALE; PIMENTEL, 2011), a qual possibilita a determinação de qualquer termo da sequência sem a necessidade de conhecer o termo imediatamente anterior.

Para Vale e Pimentel (2011), é necessário que tanto alunos quanto professores vivenciem experiências de aprendizagem com o uso do raciocínio funcional, o qual permite relacionar qualquer termo com a respectiva ordem $\mathrm{e}$ fornece uma descrição sobre o modo de conhecer qualquer termo da sequência.

Voltando ao problema, para um termo do padrão na posição $n$, o número de cartões (C) que devem ser acrescentados é dado por: $C(n)=2+(n-1) \times 3$. Todavia, para o aluno chegar a essa expressão, é essencial que conecte mentalmente a uma ideia, a qual é o significado do símbolo, de modo que, sem ela, o símbolo é vazio (SKEMP, 1989).

O próximo grupo contemplou outras duas atividades (questão 13 da prova de 2016 e questão 19 da prova de 2014), nas quais o padrão é construído por justaposição de figuras geométricas. É solicitado, então, o perímetro das figuras 
encontradas em uma determinada posição, e não mais a quantidade de elementos que formam esse termo da sequência, como no grupo anterior de questões. Aqui, o aluno deve observar o padrão do contorno das figuras ao justapor novos elementos. Como exemplo, apresentamos, no Quadro 6, uma dessas atividades, acompanhadas, a seguir, de sua resolução.

Começando com um quadrado de $1 \mathrm{~cm}$ de lado, formamos uma sequência de figuras, como na ilustração. Cada figura, a partir da segunda, é formada unindo-se três cópias da anterior. Os contornos destacados em vermelho das quatro primeiras figuras medem, respectivamente, $4 \mathrm{~cm}$, $8 \mathrm{~cm}, 20 \mathrm{~cm}$ e $56 \mathrm{~cm}$. Quanto mede o contorno da

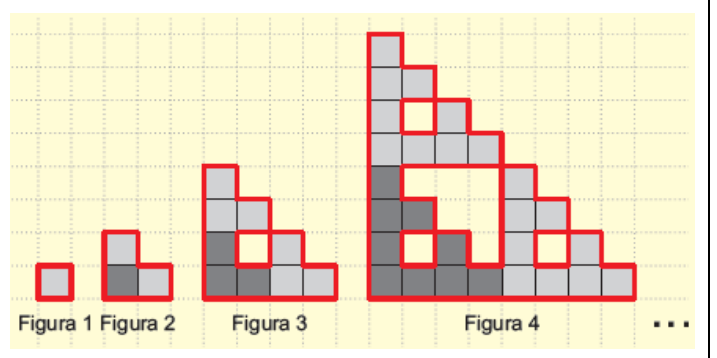
Figura 6?

Quadro 6: enunciado da questão 19 da prova da OBMEP - nível I de 2014 Fonte: www.obmep.org.br

Analisando a situação proposta, verificamos que cada figura a partir da segunda é formada por três cópias da figura anterior, justapostas de modo que apenas dois pares de lados de quadradinhos coincidam. Logo, o contorno de cada figura será igual ao triplo do contorno da figura anterior, descontados os dois pares de lados em comum. Assim, temos que a figura 1 possui contorno igual a 4; a figura 2 tem contorno igual a três vezes o contorno da figura 1, descontados os dois pares de lados comuns, ou seja, $3 \times 4-4=8$; a figura 3 é formada por três cópias da figura 2, portanto seu contorno será igual a $3 \times 8-4=20$; a figura 4 terá como contorno $3 \times 20-4=56$; a figura $5,3 \times 56-4=164$, e, por fim, a figura 6 , $3 \times 164-4=488$.

Em problemas como esse é possível utilizar o raciocínio recursivo para determinar uma expressão algébrica que determine o valor de um termo em uma posição $n$, conhecendo o valor do termo na posição anterior $(n-1)$. Esse tipo de raciocínio possibilita o que Vale $(2012,2013)$ e Vale e Pimentel (2011) denominam de generalização próxima, ou seja, é possível determinar termos consecutivos a partir do reconhecimento da diferença entre eles. 
Na situação proposta, é possível determinar uma expressão que forneça o perímetro de uma figura na posição $n(P(n))$, em função do perímetro da figura na posição anterior $(n-1)(P(n-1))$. Basta observar que o perímetro na posição $n$ é igual ao perímetro da posição $(\mathrm{n}-1)$, diminuído em quatro unidades. Logo, $P(n)$ é dado por $P(n)=3 \times P(n-1)-4$, ou seja, $3 \times P(n-1)-P(n)=4$.

Ao determinar uma expressão como essa, conseguimos encontrar valores de termos em posições sucessivas em uma sequência, o que caracteriza padrões de crescimento que abordam generalizações próximas.

Nesse sentido, Barbosa e Vale (2013, p. 3075), evidenciam que problemas de com esse tipo padrão são caracterizados por solicitarem "que os alunos encontrem uma relação entre os elementos do padrão e a sua posição e que usem esta generalização para gerar elementos noutras posições".

Sendo assim, pelas análises realizadas, constatamos que os problemas envolvendo padrões visuais e/ou figurativos de crescimento encontrados nas provas da OBMEP vão ao encontro dessa característica, uma vez que possibilitam tanto o desenvolvimento do raciocínio recursivo quanto as noções do raciocínio funcional.

\section{Considerações finais}

Neste trabalho, apresentamos um estudo sobre como as provas da OBMEP nível I (primeira fase) exploram padrões em contextos visuais e/ou figurativos. Para tanto, a partir de um estudo documental sobre tal temática, buscamos identificar, categorizar e analisar as questões presentes nas referidas provas, realizadas entre os anos de 2005 e 2018.

Inicialmente, observamos que padrões em contextos visuais e/ou figurativos é um tema recorrente nas provas da OBMEP, em especial nas provas realizadas a partir de 2012, tendo maior ocorrência no ano de 2014. Das questões analisadas, $60 \%$ abordaram padrões de repetição e $40 \%$ padrões de crescimento.

No primeiro grupo, encontramos questões que demandavam a determinação de uma unidade de repetição em uma única sequência de termos, 
em duas sequências coordenadas ou ainda, como elemento necessário a uma estratégia de contagem de muitos termos. No segundo, identificamos questões envolvendo problemas de generalização próxima, nos quais um dado termo é determinado a partir da relação constante entre termos consecutivos, e problemas de generalização distante, em que, a partir da relação entre os termos da sequência e sua posição, é possível determinar qualquer termo, sem a necessidade de conhecer o termo imediatamente anterior.

Verificamos que algumas atividades, em especial aquelas que envolvem padrões de repetição, apresentavam enunciado e resolução complexos para o nível de ensino ao qual se destinam. Acreditamos que esse fato é devido a um dos objetivos das olímpiadas que é descobrir novos talentos em matemática.

Além das questões envolvendo padrões em contextos visuais e/ou figurativos, percebemos que em diferentes provas da OBMEP estão presentes questões explorando padrões numéricos, tanto de repetição quanto de crescimento, as quais não foram analisadas por não serem o foco deste trabalho.

Considerando o papel da exploração de padrões no processo de ensino e aprendizagem matemática, sobretudo, aqueles desenvolvidos em contextos visuais e/ou figurativos, acreditamos que o presente estudo possa ser ampliado

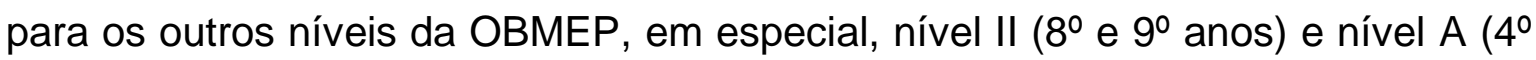
e $5^{\circ}$ anos). O destaque para esses grupos é devido ao fato do Ensino Fundamental ser a fase em que os estudantes têm os primeiros contatos com esse importante elemento do pensamento matemático: observação e reconhecimento de padrões ou regularidades.

\section{Referências}

ARCAVI, Abraham. The role of visual representations in the learning of mathematics.

Educational Studies in Mathematics, n. 52, p. 215-241, 2003.

BAQUEIRO, Grace Dórea Santos. Achados sobre generalização de padrões ao "garimpar" pesquisas brasileiras de educação matemática (2003-2013). 2016. $226 f$. Tese (Doutorado em Educação Matemática). Pontifícia Universidade Católica de São Paulo - PUC/SP, São Paulo, 2016 
BARBOSA, Tatiana Albieri. A calculadora como "alavanca" para a generalização de expressões relativas às progressões geométricas. 2013. 166f. Dissertação (Mestrado em Educação Matemática), Pontifícia Universidade Católica de São Paulo - PUC/SP, São Paulo, 2013.

BARBOSA, Ana; VALE, Isabel. A resolução de tarefas com padrões figurativos e a generalização. In: Congresso Ibero-Americano de Educação Matemática, VII, 2013, Montevideo. Anais... Montevideo, 2013, p. 3073-3081. Disponível em:

$<$ http://cibem7.semur.edu.uy/7/actas/pdfs/273.pdf>. Acesso em: 25 nov 2018.

LÜDKE, Menga; ANDRÉ, Marli Eliza Dalmazo Afonso de. Pesquisa em Educação: abordagens qualitativas. 2.ed. Rio de Janeiro: EPU, 2013.

NARDELLI, Renan Eduardo. O estudo de simetrias com frisos e questões da OBMEP. 2015. 62f. Dissertação (Mestrado Profissional em Matemática em Rede Nacional - PROFMAT), Universidade Federal de São Carlos, São Carlos, 2015.

PIMENTEL, Teresa; VALE, Isabel. Os padrões e o raciocínio indutivo em matemática. Quadrante, v. 21, n. 2, p. $29-50,2012$.

SKEMP, Richard. Mathematics in the primary school. London: Routledge, 1989.

VALE, Isabel. As tarefas de padrões na aula de matemática: um desafio para professores e alunos. Interacções, n. 20, p. 181-207, 2012.

VALE, Isabel. Padrões em contextos figurativos: um caminho para a generalização em matemática. Revemat, v. 08, n. 2, p. 64-81, 2013.

VALE, Isabel; PIMENTEL, Teresa. Padrões e conexões matemáticas no ensino básico. Educação Matemática, n. 110, p. 33-38, 2011.

VALE, Isabel; PIMENTEL, Teresa. O pensamento algébrico e a descoberta de padrões na formação de professores. Da Investigação às Práticas, v. 03, n. 2, p. 98-124, 2013. 